American Research Journal of Business and Management

(ARJBM)

ISSN (Online) : 2379-1047

Volume 2016, 4 pages

Research Article

Open Access

\title{
Generational Analysis in Educational Organizations
}

\author{
Mona Alsolami \\ Saint Louis University, United States
}

Abstract: The purpose of this paper is to identify the differences between generations in different period of times from 1946 to 2000, and how each type is very distinctive in some aspects. There are four types of generations: traditionalists, Baby Boomers, Gen-Xers, and Nexters. This paper clarifies how those generations have been affected by their environment and how their characteristics affected the communities they lived in.

\section{Generational Group Influences in ORganizational Culture}

Several studies stated that general groups affected by surrounded environment. Organizational culture impacts people in home, school and work. According to Saphier \& King (1985) people have different ideas and perspective about their communities. They also experience and sharing social experiences in their life. These groups expose different characteristics to the organizational culture that would be of significance or problematic to the society in the near future and present times. The generational group would be different in terms of the effects it exposes to the either students in current education sector or the doctors in the past that never used technological equipment.

\section{TYPES OF GENERATIONAL GROUPS}

There are four generations groups that affected organization culture which lead us to discuss them in different methods. They include traditionalists, Baby Boomers, Gen-Xers, and Nexters (Nicholson, 2008). There are factors that lead to the existence of the many groups of the familial generations such as the demand for the cheap labor which gave it a chance in the creation of employment opportunity (lovely, 2005). While is not matter about the start and the end of each group time, each group represents unique experiences and cultures. Also, each generation has specific life characteristics because of the nature of their life (Lovely, 2005).

\section{(a) Traditionalists}

This type of generation was believed to have emerged prior 1946s during the great depression and before the world war two (Nicholson, 2008). This generation by now constitutes about ten to fifteen percentage of the total population. It takes into consideration, the individuals who have retired from the governmental offices and had supernormal duties if any has been still been appointed. They considered being hardworking in any given chance of an opportunity since they lived long in harsh environmental of inadequate resources hence given a chance they can perform to the best of their abilities (Nicholson, 2008). This group takes into account the maintenance of law and order in their times so as to socially develop their capacities in the community projects and positively benefits from each other (Lovely, 2005). This generation also believed in taking the initiative of carrying out the given responsibilities in their respective field of study. Thereafter they could get the pleasures of life only after the hard work in their societal responsibilities (Lovely, 2005). It is also observed that this generation believes or reveals the aspect of being patient in the event of being successful from the projects given as their duties. Many companies need to bring this generation back to work because they have wisdom 
and accumulative experiences (Lovely, 2005). This generation also is believed to behave or conduct themselves within the socially accepted standards and constitution. For example, my grandfather, who is a ninety years old, likes to work hard at his farm during the day. My uncles brought some labors to do the farm's work instead of him; however he cannot stay without going and working hardly with them. So, he told my uncles that his happiness is tied with any achieved work and he thinks that he owns his way through hard work. Beside his hard work, he values traditional morals and wisdom. He solves all our family problems and people appreciate and respect him because of his wisdom and assistance.

\section{The Baby Boomers Generation}

This group considered to have come up after the World War II between the periods of 1943 to 1960s. In this period, the generation is believed to grown up at the time of prosperity. The generation has contributed up to about forty-five percentages of the total workforce to the real time situation today as most of them are about sixty years of age. It is that generation that would take the initiative of strongly advertising their projects in a more beneficial and positive way to the society to win the hearts of the community. They considered education as the most essential asset in their lives. This enabled them to work even better to an extent of the applying the skills of their parent to the individuals than to the company itself (Nicholson, 2008). This generation also took the task of working with each other to accomplish a given project better. This is because they would involve their groups in identifying the community problem hence through detailed and proper decision made by the group. They end up working towards the goal thus more focused team work from the generation (Bolman, \&Deal, 2013).

It also takes the act of showing confident about the tomorrow's real life situations. Reason behind is because they took into consideration the ability of hard work from the parental ethics and way of life and made it possible to implement with interest their duties (Nicholson, 2008). This generation is about 80 millions in the U.S which represents the largest population. For example, my professor Ana who is about sixty years old always tells us about her achievement and how she works hard. She told us about her motivation when she attends to achieve anything. She believes that cooperation in working as a team, is the secret behind any successful. So, she was proud about the advancement of department of special education at Flinders University and she related this to parents and professors who work as a team when they assigned their goal and cooperated to achieve it.

\section{The Gen- Xers Group}

It is a generation that came into existence after the baby boomers, between the years of 1965s and 1980s (Nicholson, 2008). They are believed to come from the time when there was a diminished workforce level in the society (Nicholson, 2008). The generation gave an idea of next level work inclusive of self-employment that would now motivate them work even better to their best of their abilities. They are independent workers who need little direction and like to work on their terms on their free time (Durkin, 2008). They also concerned with working to an extent of converting the social activities of the community into a global village where real life activities are operated within hence easy access to the modernized. The generation further takes the opportunity of information technology taught in class to the extent of real life application in the event of solving the social tasks within the society. Also, this generation does not care about bureaucracy because they follow their values and attitude (Lovely, 2005). Alongside they are technological; they balance between work and life. For example, my sister is very intelligent in using technology while her major is teaching English as a second language. Although she has hard work at her school, she is very keen to coordinate between her work and her life. Furthermore, she is multitasking because she can do two jobs in the same time. I remember when we visit her; she was preparing her job needs, her four children and husband needs in the same time. 
The Gen- Yers Group

It consists of a group of an individual right after the generation $\mathrm{x}$ and they were born in the period of 1982 to 2000 (Reynolds, Bush \& Geist, 2008). To involve this group in work place, companies need to adapt new strategies such as style, context, content and hurry and repetition. They like to be told what to do at home and schools and they like to have obvious instruction in order to achieve it (Durkin, 2008). This generation also likes the change on jobs and they cannot stay for long time working on the same place. So, they are less loyal to their companies; (Durkin, 2008). As a result, four people in ten Gen Yers are at risk of leaving their job because they do not engage with environmental work (Durkin, 2008). On contrast, they believed that they have the ability to make noticeable change in the world. Also, they are optimistic about achieving their goals which are being famous and rich (Durkin, 2008). They like to express their voice as well as the want to know logical of making decisions (Reynolds, Bush \& Geist, 2008). An example, my younger brother who is 24 years old, till now, he went through three different jobs. He was a teacher, then he employed at constructional company and now he is social work specialist. In all three jobs he was in a good position however, he does not like to stay long time in one job. Also, he some time fights with his boss because the lack of feedback and some free time during the job time. One time I talked with his baby boomer manager and he told me about the hardness of dealing with all workers who are the same of my brother age.

\section{The Comparison between the Baby Boomers and THE Generation X Category of GROUPS}

In terms of work code of conduct the baby boomers are interested in challenging the organizations operation workers to know more of the advanced technology, while the generation $\mathrm{x}$ have no time for the challenges instead they focus on the work given at hand hence attempt to maintain their lives.

The baby boomers acquired the hard way the use of information technology while the generation $\mathrm{x}$ used the assimilated the informational advancement of technology hence assured the development to the society as well.

The baby boomers have always been considering the opportunity of given job from their constitutional offices as a career. This is not the case with the generation $\mathrm{x}$ in the event of being given a job they take it as a contract basis project. That is; it should be done for a particular period hence set free for another project.

The baby boomers focus is mainly on the relationships within the organization and work while on the other side the generations $\mathrm{x}$ group will always focus on the work and payment strategy after the whole project is finished.

The baby boomers were born form the ranging ages of (1946-1964) aging 44-62years of age. They are considered to be the role models in the societal world in an attempt to get the whole successful information from them.

As the generation $\mathrm{x}$ group see togetherness as the way of times wasting in financial gains, they therefore work independently as the baby boomers involve themselves since they are aggressive in knowledge rather than the payments after projects like the generation $\mathrm{x}$ does. This, therefore, makes some balance status in the society that leads to the growth and development. As each group will be taking the initiative of their specific roles in the community at large.

\section{Advantages of Generational Groups}

\section{Communication}

this has been enabled by the groups themselves through series of continued integration among themselves in exchange knowledge and beneficial ideas. 


\section{Awareness}

this has enabled the employees within a company to work with a productive mind in the creation of the business maximum profits hence the actual way. This can also enable an organization to establish more professional business policies that would guide the organizational operations in the end, to achieve its objective goal.

\section{Teamwork}

This has been observed among the baby boomers generational group since it can always seek for knowledge rather than contractual projects in the process.

\section{Information technology advancements}

This took place as a results of the of the generation $\mathrm{x}$ and $\mathrm{Y}$ adapting to the skills acquired from their parents' skills that used the advanced education of computers and internet to diversify their research and studies

\section{CONCLUSION}

It has been evident that as the generational groups transpose from one level to another, a beneficial feature is achieved or lost in the next generation as per what was done in the early stages. For example, the generation $\mathrm{x}$ takes it for granted the aspect of sharing ideas and acquisition of knowledge through long-term procedure yet; they want payments on a contract basis which doesn't last for long. These generations through different beneficial strategy that is socially accepted, there has been improvement of the living standards among the community members as a whole.

\section{REFERENCES}

Bolman, Lee G.; Deal, Terrence E. (2013). Reframing Organizations: Artistry, Choice and Leadership.

Durkin, D. (2008). Youth Movement. Communication World, 25(2), 23-25.

Lovely, S. (2005). Creating Synergy in the Schoolhouse: Changing Dynamics among Peer Cohorts will Drive the Work of School Systems. School Administrator, 62(8), 30.

Nicholson, N. (2008). Empower the Next Generation. Communication World, 25(2), 14-19.

Reynolds, L., Bush, E. C., \& Geist, R. (2008). The Gen Y Imperative. Communication World, 25(2), 19-22.

Saphier, J., \& King, M. (1985). Good seeds grow in strong cultures. Educational leadership, 42(6), 67-74.

Citation: Mona Alsolami, Generational Analysis in Educational Organizations. ARJBM Volume 2016; pp:1-4

Copyright (C) 2016 Mona Alsolami, This is an open access article distributed under the Creative Commons Attribution License, which permits unrestricted use, distribution, and reproduction in any medium, provided the original work is properly cited. 